and universities, and the field has been growing in popularity. In contrast, there are few places inJapan to study the United States, and few experts in Japanese academe specializing in the United States; the field of American studies is underdeveloped in Japan.

What is to be done? There is an urgent need to correct dramatic imbalances in educational and cultural relations. It is clear that some inequalities will remain. Large numbers of Americans are simply not going to learn Japanese-it is a language that requires a great deal of time and energy to master, and its usefulness is limited to Japanalthough there ought to be further growth in the numbers of Americans studying Japanese. With only minor improvements in language instruction in Japan, large numbers of Japanese can be sufficientlyfluent in English to communicate with Americans and other English-speakers.

The main challenge is to recognize that there is adistinct knowledgedeficit, and that education and culture are very muchpari of thepatterm of internotional relations in the modem world.

Better policies and performance in education and cultural exchange and learning do not require treaties or diplomatic ann-twisting. Modest initiativescan go a long way. Here are some suggestions:

- Improve and expand already existing programs to bring Americans to Japan for study. This can be done by better publicity and coordination, and o modest infusion of resources. At present, 90 percent of the foreign students in Japan are from Asia. More attention can be placed on attrocting students from the United States.

- Stimulate the translation into English and publication of more Japanese books in the United States. This con be done through commercial publishers with subsidies for translation.

- Expand the study of the United States in Japan and provide resources for training experts on American culture, history, politics, and society.

The main challenge is to recognize that, while there might be a trade surplus in Japan's favor, there is a distinct knowledge defiat, and that education and culture are very much part of the pattern of international relations in the modem world.

(This article appearedin the fapan Times [Tokyo], October 7,1995)

\section{Jesuit Higher Education in India Today Institutionalizing Our Charism in the Affiliating University}

\section{Rudolf C. Heredia, s.}

RudolfC. Heredia, SJ. is on the stoff of the Social Science Center, St. Xaviers College, Bombay, India. Address: Social Science Center, St. Xavier's College, Bomboy, INDIA 40001

$\mathbf{T}$ The dialectic tension between the "institutional" and the "charismatic" is inherent in any social system. Indeed, charismatic inspiration and authority need institutionalization for continuity; yet at the same time, it is alienated by these very structures. While the dialectic between these two necessary polarities constitutes an inescapable dilemma, the tension between them could be a source of creative growth and innovative adaptation - rather than of confusion or ossification, as would happen if only one or the other horn of the dilemma were stressed. Religious organizations illustrate this very convincingly. Consider the beginnings of a church or religious congregation, where the early charism of the founder(s) is institutionalized in later structures, precisely to extend it over time and space. Educational institutions, too, particularly when they derive from a religious, or otherwise charismatic inspiration, are also subject to this dialectic tension, and Jesuit education certainly falls into this category.

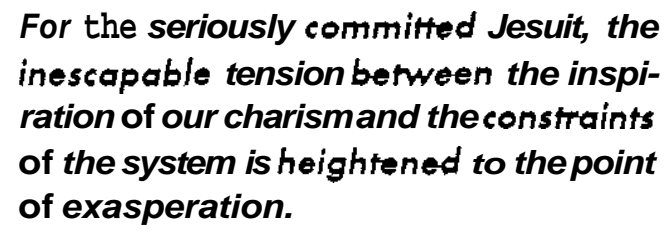
inescapable tension between the inspiration of our charismand the constraints of the system is heightened to the point of exasperation.

Jesuit educational institutions are an important apostolic commitment ofthe Society of Jesus. Indeed, the education ministry was one of the earliest apostolates of the Society, and today one of its largest commitments as well. St. Paul's College in Goa, which the Jesuits took over in 1549 , was one of the earliest colleges of the Society of Jesus, and one of the first Western institutions of higher education in India. Giving expression in this ministry to our Jesuit charism and the mission it calls us to has always been a challenge, and an increasingly difficult one today-especially in this country and most particularlywith higher edu- 
cation here. This is not because our charism and our mission today and tomorrow, as once again affirmed by our most recent General Congregations, have no relevance for this country, but rather because the institutional constraints of the educational system here are becoming increasingly problematic: overbureaucratization,excessive governmental control, inadequate finances, and widespread politicization, to mention but a few of the problems plaguing the system. Moreover, for lack of political will, even carefully worked out and much-needed reforms have time and again been stymied. In fact, the very relevance of the system is being questioned and it is fast losing credibility, but as yet, no alternative to the present formal system has emerged to replace it.

The affiliating university has aptly been described by the well-known educationist, Suma Chitnis, as a "minimum demands system" for all the constituencies involved: students, teachers, administrators, and government officials. As such, it creates powerful vested interests that resist change. This progressively alienates the university and its colleges from changing social realities and needs. In the post-Independence period this is glaringly apparent.

More recently, the 'autonomous colleges," first recommended by the National Education Commission 1964 66, are a promising innovation that might well provide a breakthrough for undergraduate education in the affiliating university. Jesuit institutions have welcomed the recommendation, and most would certainly qualify for selection. But as yet, few universities are willing to grant such autonomy, and where they have, the scale of implementation has been more symbolic than significant. Indeed, only in South Asia does the original form of the centralized affiliating system survive. Elsewhere, various degrees of autonomy, academic and otherwise, for the affiliated institutions of the university have long been a necessary decentralization as the system grew unmanageable.

Jesuit higher education in India is mostly located in undergraduate colleges today. These are among the most prestigious in the country. But, paradoxically, their very success within this system has become their own worst enemy. For institutional prestige all too easily becomes the measure of academic excellence. When this is in an academic system that by our own admission has become increasingly irrelevant educationally, in terms of a positive contribution to the needs of a changing society, can such "excellence" be an authentic expression of Jesuit commitment today? This is a difficult and painful question that must he squarely faced in the light of recent Jesuit understandings of our mission today. For in the final analysis, institutional structures are but means, albeit necessary ones, and hence they cannot he allowed to displace educational goals andvalues, which must be derived from the vision that inspires the Jesuit mission.

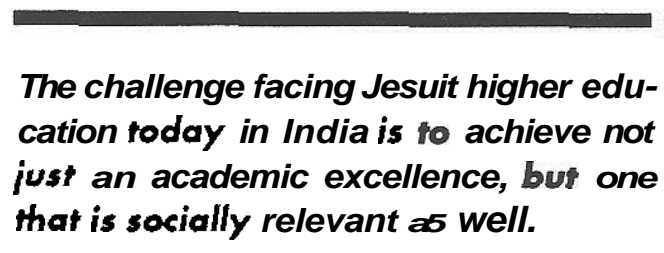

More specifically, the challenge facing Jesuit higher education today in India is to achievenot just an academic excellence, but one that is socially relevant as well. The institutional expression of such relevance, at a first level, must be in terms of the people we have opted to serve. Thus, admission criteria must express our option for the poor, and not be based solely on a class-biased merit system that negates this. For a "meritocracy"will be as unjust as an aristocracy, in a class-caste-ridden societysuch as ours, where equality of opportunity is severely constrained and access to good education is limited from the earliest stages.

At a second level, besides the students we select, the graduates we produce must be, in Fr. Arrupe's words, "men for others" and "agents of change" for justice and faith. Course content and administrativestructuresare hut means to be geared to these pedagogic goals. Obviously, there are the constraints of the system, particularly acute in the affiliating universities in this country. But the challenge is precisely to use what freedom we have to create the freedom we want, rather than find alibis for continuing with the status quo.

At a third level, such in-house goals must be complemented with out-reach programs in terms of an extension service that is compatible with the pedagogic commitments of an educational institution. This is sometimes called "service education,"which really amounts to education through service. The institutional goodwill and the professional and other resources of a prestigious college can indeed make a real contribution to the local community and beyond. The specific contribution could vary from making institutional facilities available to the neighborhood, to advocacy programs, and engaging faculty and students on issues of social concern.

In addition to community service, afourth level of relevance for a Jesuit college could well he in research that is action-oriented on issues of social concern, particularly those issues that are neglected by professional academics. In fact, Jesuit colleges in India did cultivate a strong research tradition as long as they had graduate departments. 
Once these were centralized in the university, the emphasis shifted to undergraduate teaching. But research today opensinto a much larger space than the academicgraduate world. There are nongovernmental agenciesthat are leaders in new areas of research, where the Jesuits would be challenged to revive their lost tradition.

A "Study of Jesuit Collegesin India" by Fr.John Macia in 1982, concludes with "the conflict between two organizational goals: (a) the pursuit of academic excellence, (b) the promotion of greater social justice." In the present context of the affiliating university in this country, our mission today indicates an obvious choice in favor of the second. The new economic policies being adopted in the country, which are likely to hasten growth and certainly sharpen inequalities, only make this choice all the more urgent. The real creative challenge is not in the resolution of this played-out goal-conflict, hut rather in the dialectic tension between a critical intellectual quest and an effective commitment to education for justice. This, we believe, must be the real creative challenge for Jesuit higher education in India on the threshold of the 21 stcentury.

International Higher Education Online

Announcing the World Wide Web site of the Boston College Center for International Higher Education, the first of its kind to offer information resourcesto scholars of both higher education and international affairs.

HTTP://WWW.BC.EDU/BC_ORG/AVP/SOE/CIHE/ Center.htme

It is recommended to use Netscape 1.1 or a similar graphical browsertoaccess the above location, which offers a wide variety of online resources, including: full text versions of the Center's newsletter, International Higher Education, library and data information resources, scholarly exchange and research funding resources, online journals in the field of higher education, and international news resources.The Center has already received recognition from Point Communications, a well-known leader in information technology, that the Web site is in the top $5 \%$ of all Internet resources in terms of quality, and has been incorporated by Yahoo, Lycos, the Internet Yellow Pages, and other popular Internet directory services.

\section{Currency and Crisis}

\section{Higher Education in Francophone Africa}

\section{Corbin Michel Guedegbe}

Corbin Michel' Guedegbe is project manager for a U.S. Agency for International Developmentfunded education reform project in Benin. He has been a division chief in the Ministry of Educofion of Benin: Address: B. P. 034688, Colonou, Benin

A frican higher education has been in crisis since the 1980 s - in contrast to the 1960 s and 1970 s, whichwere periods of lavish spending and expansion. This crisis was exacerbated in the 1990s by worsening economic conditions and the constraints of structural adjustment programs (SAP). Most features of the crisis are common to francophone and anglophone African countries. However, some aspects are unique to francophone Africa and are due to factors internal and external to higher education. This article gives an overview of the situation in Africa, in general, and focuses on the francophone part of the continent.

Increasingenrollments, unsustainable expenditure patterns, declining quality, and irrelevance to national needs have been mentioned as problems common to universities in sub-Saharan Africa.' This accounts for the fact that among the three main outputs of higher education (i.e., high level manpower, knowledge and innovation, and development advisory services), the region bas produced relatively too much of the first and not enough of the second and the third. The overproduction of graduates and the deterioration of quality are major characteristicsof the current crisis in higher education in Africa. The consequence of the overproduction of graduates is the considerable unemployment and underemployment among graduates of African universities. Some features of the deterioration of standards are: 1) the low quality of teaching, and 2) the low internal efficiency resulting from high drop-out rates, which increases the cost per graduate, and the unnecessarily high costs of higher education home by the education budget of African countries.

\section{Common Problems}

Although most aspects of the crisis of higher education are common to the entire sub-Saharan region, certain processes particular to the francophone higher education systems as well as the devaluation of the currency of these countries (the CFA Franc) in January 1994have exacerbated the crisis of quality in the francophone area of Africa. The tradition of free university education inherited from France has led to a dramatic increase of student numbers. Until now, 